\title{
Dificuldades de Coordenação e Políticas Educacionais no Brasil: O Caso do Ensino Fundamental
}

\author{
Haroldo da Gama Torres ${ }^{1}$ \\ Rafael Camelo ${ }^{2}$ \\ Maria Helena Guimarães Castro ${ }^{3}$ \\ ${ }^{1}$ Doutor em Ciências Sociais. Universidade Estadual de Campinas (UEC). Campinas, SP. Brasil. \\ E-mail: hgtorres@uol.com.br, https:/ / orcid.org/0000-0002-5965-0118 \\ ${ }^{2}$ Doutor em Economia. Escola de Economia de São Paulo (EESP). Fundação Getulio Vargas (FGV). \\ São Paulo, SP. Brasil. \\ E-mail: rafael.camelo@gmail.com, https:/ / orcid.org/0000-0003-4086-3292 \\ 3Professora aposentada da Universidade Estadual de Campinas (UNICAMP). Campinas, SP. Brasil. \\ E-mail: mariahelenacas@gmail.com, https:/ / orcid.org/0000-0003-1998-2887
}

\section{INTRODUÇÃO}

\footnotetext{
$\mathrm{Q}$
} uase todas as políticas públicas impõem a necessidade de coordenação entre níveis de governo e agentes responsáveis pela provisão dos serviços. Isso é particularmente relevante no caso dos serviços prestados de forma descentralizada (característica da maior parte das políticas sociais no Brasil). Na prática, para cada política específica, as formas de coordenação podem ser reguladas ou não. Além disso, podem estar presentes mecanismos específicos (como os pactos) que visam assegurar que a cooperação entre diferentes esferas de governo ocorra. No entanto, mesmo quando leis e mecanismos existem, eles podem funcionar com menos ou mais efetividade. Em outras palavras, dependendo da política pública em questão, pode ser frequente a ocorrência de "falhas de coordenação".

Em termos mais gerais, as chamadas falhas ou problemas de coordenação dizem respeito a questões clássicas dos campos da economia do desenvolvimento e da ciência política (Cooper e Andrew, 1991; Cox, 1997). Elas ocorrem em situações em que os agentes responsáveis pela oferta de serviços têm dificuldades de coordenarem suas escolhas e ações, levando a resultados pouco efetivos (ou "subótimos") no âmbito daquela área. Em outras palavras, na ausência de

DADOS, Rio de Janeiro, vol.62(4):e20170226, 2019. 
coordenação, os resultados são piores do que se essa coordenação estivesse presente e funcionasse a contento.

Apesar da sua grande relevância, a produção acadêmica sobre os temas de coordenação é relativamente limitada no Brasil. Na área da educação, o tema tem sido discutido tendo por base o emprego da expressão "regime de colaboração" e envolve, sobretudo, o debate a respeito dos arranjos entre diferentes níveis de governo na oferta da política educacional (Santos e Gisi, 2017; Castro, 2015; Sales e Silva, 2013; Morduchowicz e Arango, 2010; Costa e Duarte, 2008; Tavares, 2003).

Porém, discutir as questões da coordenação da educação básica no Brasil não é nada trivial. A tarefa demanda talvez um nível de complexidade inédito em termos mundiais. Isso ocorre tanto pela diversidade de tipo de provedores (públicos, privados e não governamentais), quanto pela diversidade de funções realizadas pelos diferentes níveis de governo. Afinal, os municípios são os principais responsáveis pela oferta de educação infantil (de zero a cinco anos); estados e municípios respondem pela oferta conjunta de Ensino Fundamental do primeiro ao nono ano (de seis a catorze anos); e os estados são os principais responsáveis pela oferta de Ensino Médio. A União, por sua vez, tem papel supletivo em relação a todos os níveis de educação básica e cumpre importante função na coordenação das políticas e na avaliação do sistema educacional. É também responsável pela regulação, supervisão e financiamento da rede federal de ensino superior que inclui as instituições próprias e o sistema privado.

De certa forma, pode-se dizer que o Brasil possui 5.645 sistemas municipais de ensino básico (que podem ou não se integrar ao respectivo sistema estadual), e 26 sistemas estaduais, além do Distrito Federal. Isso significa que, num mesmo território podem conviver escolas e alunos de sistemas estaduais e municipais com autonomia para definir currículo, formação e carreira de professores, recursos didáticos e planejamento da organização escolar, por exemplo. Nesse complexo sistema, estudam 50 milhões de alunos em mais de 200 mil escolas públicas e privadas onde atuam cerca de 2 milhões de profissionais de educação. Diante desse quadro, uma hipótese bastante plausível é que as questões de coordenação estejam no cerne dos problemas de implementação das políticas educacionais no Brasil, apesar de - surpreendentemente - serem discutidas de modo limitado. 
Na próxima seção, especificamos em mais detalhe o que entendemos por problemas de coordenação e aportamos algumas de suas variantes na política educacional brasileira. Em seguida, apresentamos um estudo empírico baseado em um painel longitudinal de municípios para o período de 2007 a 2011, em que se tenta evidenciar que as questões de coordenação importam. A partir da construção de um indicador de migração de alunos entre as redes de Ensino Fundamental municipal e estadual, buscamos mostrar que a baixa coordenação entre estados e municípios tem impacto do ponto de vista do desempenho escolar. Ao final, apresentamos uma breve discussão.

\section{DIFICULDADES DE COORDENAÇÃO}

Frequentemente as questões de coordenação têm sido discutidas no Brasil e na América Latina no âmbito de abordagens sobre o federalismo (Arretche, 2009; LAC/Banco Mundial, 2010). Isso faz certo sentido no Brasil, pois a Constituição Federal de 1988 é relativamente recente e, a partir dela, houve um ímpeto importante na direção à descentralização de políticas sociais com modelos que envolvem maior ou menor grau de controle dessas políticas por parte do governo federal.

Muito provavelmente, arranjos institucionais tão recentes engendram processos de ajuste e aprendizagem no âmbito de uma dada política que podem induzir a diversos problemas de coordenação. No entanto, é preciso destacar que o tema do federalismo não esgota a questão da coordenação, sendo que dificuldades nessa área podem ocorrer tanto em contextos de países federativos quanto unitários, ou mesmo ao longo das diversas etapas do processo de implementação de uma dada política executada por um único ente federado ${ }^{1}$.

Charbit (2011), por exemplo, descreve sete dimensões distintas que podem levar a problemas de coordenação entre diferentes agentes de implementação quando executando uma dada política pública. ${ }^{2} \mathrm{Em}-$ bora essa tipologia não seja necessariamente exaustiva, ela oferece de modo bastante simples uma boa descrição das várias possibilidades existentes:

1. Problemas decorrentes de níveis assimétricos de informação entre gestores de diferentes esferas de governo, que ocorrem quando da implementação e execução de uma dada política descen- 
tralizada. Por exemplo, a informação sobre como acessar um determinado programa federal pode não chegar adequadamente na esfera municipal ou, ao contrário, práticas locais contrárias aos princípios de um dado programa federal podem não ser percebidas pelos gestores centrais desse programa;

2. Problemas relacionados ao baixo nível de capacitação de recursos humanos e acesso precário à infraestrutura, limitando a capacidade de gestores de uma política executar determinada tarefa. Embora essas dificuldades sejam mais comuns em escala local, como em escolas localizadas em áreas vulneráveis, por exemplo, elas também podem ocorrer na esfera estadual e federal, dependendo do programa em questão;

3. Dificuldades relacionadas aos diferenciais de arrecadação e de níveis de receita per capita nas diferentes unidades da federação responsáveis pela execução da política. Esse é um problema bastante importante em países com elevado nível de desigualdade regional, como o Brasil, que convive - no caso da política educacional - com gastos por aluno/ano muito distintos dependendo do município;

4. Falhas relacionadas ao estilo de execução de uma dada política, em particular derivadas do grau de verticalização (comando-controle) ou de pactuação de princípios e práticas entre as esferas federais, estaduais e locais ${ }^{3}$;

5. Problemas relacionados à gestão territorial da política, envolvendo economias de escala e tamanhos heterogêneos de municípios e estados. Esse é um problema típico da política de saúde, por exemplo, uma vez que um hospital que realiza procedimentos de alta complexidade tende a oferecer serviços para um raio de abrangência que pode extrapolar barreiras municipais e mesmo estaduais;

6. Dificuldades relacionadas às diferentes perspectivas dos gestores locais ou federais em relação aos objetivos de um dado programa, o que pode criar obstáculos para a adoção de uma estratégia comum. Essas falhas são mais comuns quando esses diferentes atores pertencem a agremiações partidárias distintas, mas podem existir em diferentes contextos, sendo influenciada pelos valores e 
visões de mundo dos agentes responsáveis pela implementação da política em questão;

7. Falhas relacionadas ao sistema de gestão da informação e prestação de contas dessa política (accountability). Isso dificulta a transparência sobre as práticas dos diferentes níveis de governo na gestão de uma dada política, bem como pode comprometer a realização de diagnósticos necessários à eventual correção de rumos.

8. Esses sete pontos colocados por Charbit (2011) evidenciam que existe um conjunto muito abrangente de temas que podem levar a problemas de coordenação, mesmo quando existem recursos abundantes e quando não existem problemas relacionados à questão de alinhamentos partidários. Alguns desses problemas podem ser internos a determinadas redes de prestação de serviço, outros ocorrem necessariamente no âmbito de interações entre redes distintas.

Tratar de todos esses aspectos envolve, evidentemente, um esforço de grande fôlego. Para fins do presente artigo, abordaremos exclusivamente as falhas relacionadas ao estilo de execução da política de Ensino Fundamental, em particular no que diz respeito à pactuação de princípios e práticas de gestão entre as esferas estaduais e municipais (item 4). Aprofundamos a seguir essa discussão para o caso da educação básica no Brasil.

\section{PROBLEMAS DE COORDENAÇÃO NA POLÍTICA DE EDUCAÇÃO BÁSICA}

Alguns dos problemas de coordenação em educação têm sido tratados de modo específico na literatura brasileira de ciência política. Vale destacar em particular as análises que buscam compreender os efeitos das desigualdades de receitas municipais na oferta de determinados tipos de serviço público (Arretche, 2010), e os estudos que visam discutir a relação entre preferências partidárias e implementação de estratégias específicas de cooperação entre municípios e estados (Gomes, 2008). No âmbito dos estudos educacionais, análises específicas também têm tratado da questão para temas como a formação de professores (Santos e Gisi, 2017), além de estudos de casos voltados para estados específicos como o Piauí (Sales e Silva, 2013), Ceará (Vieira e Vidal, 2013), Minas Gerais (Costa e Duarte, 2008) e Paraná (Santos, 2003). 
A política educacional é por definição complexa em termos de coordenação, pois envolve um conjunto muito diversificado de instrumentos, programas e atores. Existe no Brasil um arcabouço legal e instrumentos operacionais relacionados à cooperação para as áreas de financiamento, construção escolar, avaliação educacional e serviços de apoio, como merenda, transporte e livro didático. Recentemente, o tema do currículo foi regulado no âmbito das regras relacionadas à Base Nacional Comum para o Ensino Fundamental. Porém, cabe notar que a presença de estratégias formais de colaboração não necessariamente elimina a ocorrência de dificuldades de coordenação em áreas já reguladas.

Outro aspecto relevante é que o papel dos governos estaduais não é, em geral, claramente especificado no âmbito das estratégias de cooperação. A não ser no caso do financiamento, que detalha claramente uma regra relacionada ao papel de estados e municípios, nos demais casos, estados e municípios não dispõem de regras universais relacionadas à cooperação - mesmo tendo que oferecer de modo compartilhado o Ensino Fundamental. Quando existem, tais formatos de cooperação entre estados e municípios são estabelecidos através de convênios que podem ser firmados ou não, e que podem variar substancialmente caso a caso (Castro, 2015; Gomes, 2008).

Uma ocorrência exemplar de dificuldade de coordenação numa política já regulada diz respeito ao piso nacional salarial de professores de educação básica, criado por lei federal em 2008. Trata-se de um tema particularmente polêmico. A constitucionalidade do dispositivo da lei, segundo o qual o piso consiste no valor abaixo do qual todos os entes federados não podem fixar o vencimento inicial das carreiras de seus professores, foi questionada por cinco estados junto ao Supremo Tribunal Federal (STF).

Entretanto, apesar de o STF ter declarado a constitucionalidade do piso como vencimento inicial da carreira, dez estados não conseguiram pagar integralmente o piso nacional em 2014, segundo informações da Confederação Nacional dos Trabalhadores de Educação (CNTE). A rigor, a lei 11.738/2008 determina que o piso seja cumprido para jornadas de 40 horas, das quais um terço deve ser alocada como horas-atividade (para preparação de aulas, reuniões etc.). Portanto, se considerarmos todos esses critérios, é provável que exista um número maior de estados descumprindo a lei. 
Além disso, as diretrizes nacionais para a carreira do magistério, aprovadas em 2010 pelo Conselho Nacional de Educação (CNE) e que ainda dependem de regulamentação federal, também se chocam com a autonomia local e muitas vezes não se adéquam às condições de funcionamento dos governos municipais. Esse tema é fonte de conflito permanente na organização das carreiras dos profissionais de educação, que não raro trabalham em escolas municipais e estaduais de um mesmo município com carreiras e salários diferentes.

Outro tema de coordenação de particular interesse para o presente artigo é o da gestão escolar e do projeto pedagógico. Estamos nos referindo aqui ao planejamento conjunto da oferta de vagas, parceria em assistência técnica, apoio a projetos locais de gestão pedagógica ou curricular, implantação de avaliações de desempenho escolar, uso dos resultados de avaliação para planejamento e definição compartilhada de metas e indicadores, por exemplo.

Em parte, isso decorre do fato de que, a partir da a Constituição de 1988, os municípios passaram a ter autonomia e poder para criarem seus próprios sistemas de ensino e definirem suas políticas sem responderem a diretrizes do estado, exceto àquelas emanadas da União. Num mesmo município podem conviver sistemas de ensino distintos - estadual e municipal - e responsáveis conjuntamente pela oferta do Ensino Fundamental (de 6 a 14 anos), tendo teoricamente que cooperar entre si, mas sem uma estrutura legal formal que facilite ou assegure essa cooperação. A União, por sua vez, tem recursos para projetos e programas que são distribuídos aos municípios de acordo com suas próprias regras, mas de modo não necessariamente coordenado com os governos estaduais.

As tentativas de coordenação da política educacional - através de articulações entre governos estaduais e municípios - variam entre os estados. Em alguns deles, como por exemplo, no Paraná, os municípios são responsáveis pela oferta dos anos iniciais do Ensino Fundamental ( $1^{\circ}$ ao $5^{\circ}$ ano) e a rede estadual de ensino se concentra nos anos finais ( $6^{\circ}$ ao $9^{\circ}$ ano) e no Ensino Médio. Em outros casos, como São Paulo, a cooperação se resume a estabelecer convênios com os municípios para repassar recursos destinados a transporte, construções escolares, merendas e ações assistenciais. Mas existem exceções importantes como os casos dos estados do Ceará e de Minas Gerais. 
No Ceará, além de transferir toda a oferta de Ensino Fundamental para as redes municipais, assegurando-lhes assistência técnica, o estado concentrou-se no atendimento do Ensino Médio e inovou o modelo de governança, estabelecendo incentivos financeiros vinculados ao cumprimento de metas pelos municípios. Desde 2007, os municípios passaram a contar com apoio técnico e financeiro do estado para a gestão educacional, avaliação, formação de professores, aquisição de material didático e de apoio pedagógico (Vieira e Vidal, 2013). No caso desse estado, existem evidências de que essas práticas tiveram efeitos importantes (Costa e Carnoy, 2015). Concomitantemente à implantação desse projeto, a porcentagem dos alunos alfabetizados no fim do 20 ano do Ensino Fundamental passou de 39,8\%, em 2007, para 81,6\%, em 2013. O esforço de alfabetização é parte da estratégia de incentivos desenvolvida pelo governo do estado, que premia as escolas municipais com os melhores resultados de alfabetização. Assim, é possível que esses fatores tenham contribuído para explicar a importante melhoria do desempenho dos estudantes cearenses nos últimos anos.

Minas Gerais também adotou estratégias específicas de colaboração estado-município com a criação do PIP (Programa de Intervenção Pedagógica), desenvolvido pela secretaria estadual de educação. Com o objetivo de melhorar a qualidade de ensino nos anos iniciais, o PIP oferece acompanhamento permanente às escolas estaduais e municipais com o propósito de recomendar aos gestores e professores estratégias de intervenção pedagógica e de capacitação. O programa, inicialmente estadual, foi oferecido aos municípios mineiros e ganhou a adesão de 100\% deles. Para os anos finais do Ensino Fundamental, uma equipe oferece apoio pedagógico às redes municipais para a implementação do currículo estadual. $\mathrm{O}$ estado oferece recursos pedagógicos, instrumentos de avaliação diagnóstica, as diretrizes curriculares e capacitação aos municípios (SEE-MG, 2012).

Talvez esse tipo de coordenação entre redes municipais e estaduais não fosse um problema fundamental se as duas redes apenas competissem plenamente entre si na oferta de Ensino Fundamental, sem troca de alunos. Porém, com o advento do Fundo de Manutenção e Desenvolvimento do Ensino Fundamental e de Valorização do Magistério (Fundef), criado em 1996, passou a ocorrer uma crescente especialização dos municípios na oferta dos anos iniciais do Ensino Fundamental, enquanto a participação dos estados continuou bastante elevada nos anos finais ${ }^{4}$. 
De fato, enquanto a oferta municipal nos anos iniciais passou de quase 50\%, em 1997, para 70\%, em 2013, segundo os dados do Censo Escolar, a participação estadual no segundo ciclo do fundamental permaneceu elevada, tendo saído de $70 \%$, em 1997 , para pouco menos de $50 \%$, em 2013. Essa distribuição assimétrica de vagas entre os dois estágios do Fundamental significa que, a cada ano, milhões de alunos têm que migrar da rede municipal para a rede estadual ao fim do $5^{\circ}$ ano.

Nossa hipótese é que, em cada município, essa passagem tenderá a ser mais complexa e abrupta na ausência de regras organizadas e estáveis de cooperação, particularmente aquelas relacionadas à gestão escolar e ao projeto pedagógico. E, como consequência, isso levaria provavelmente a impactos negativos em termos de desempenho escolar. Aprofundamos essa hipótese na análise empírica detalhada na próxima seção.

\section{IMPACTO DA MIGRAÇÃO ENTRE REDES NO ENSINO FUNDAMENTAL}

Como vimos acima, os problemas de coordenação não se esgotam na questão da cooperação entre entes federativos, podendo se dar no interior das próprias redes. Isso significa que a avaliação precisa do impacto das variações nas formas de coordenação de uma dada política educacional pode exigir informação muito detalhada sobre as diferentes estratégias locais de implementação dessa política, bem como sobre as transformações ocorridas no seu processo de implementação ao longo do tempo.

Para circunscrever o problema, o que tentaremos observar é até que ponto a permanência ou migração de estudantes do Ensino Fundamental entre redes de ensino impacta ou não as variáveis educacionais de desempenho escolar. Nesse sentido, estaremos assumindo a priori que a permanência em uma mesma rede de ensino (estadual ou municipal) aumenta a probabilidade de maior presença de coordenação, enquanto a migração entre redes de ensino reduz a probabilidade de coordenação.

Em outras palavras, tomaremos a migração entre redes de ensino como proxy da existência de problemas de coordenação. Vale destacar que esta proxy é limitada, pois não capta problemas de coordenação dentro de uma única rede, como questões de coordenação entre a escola e a secretaria, entre professores e diretores etc. 
Como indicado anteriormente, a migração entre redes é relativamente comum no Brasil contemporâneo. De fato, os dados de oferta de Ensino Fundamental já evidenciavam de modo claro esse fenômeno em 2007, ano que usaremos como baseline para a análise a ser realizada mais à frente. No primeiro ciclo, quase 2.500 municípios apresentavam mais de $90 \%$ de suas matrículas na rede municipal; no segundo ciclo, mais de 1.700 municípios tinham menos de $10 \%$ dos alunos na rede municipal (Gráfico 1). Em outras palavras, em vários locais do país, as redes estaduais e municipais ofertam simultaneamente vagas em ciclos diferentes e, em consequência disso, os alunos são levados a migrar entre redes.

Assim, o exemplo mais típico considerado em nossa análise é aquele em que o aluno inicia o Ensino Fundamental na rede municipal e muda para escolas estaduais a partir do $6^{0}$ ano, quando começa o segundo ciclo do Fundamental. A ideia é que, na ausência de coordenação, as diferenças entre as políticas e práticas pedagógicas de cada rede de ensino devem afetar negativamente o desempenho dos alunos, em comparação com alunos que se mantêm sempre na mesma rede. Antes de aprofundar esse exercício, apresentamos o indicador de migração entre redes e discutimos as características das diferentes redes a partir desse indicador.

Gráfico 1

Distribuição dos municípios segundo participação da rede municipal nas matrículas públicas (Brasil, 2007)

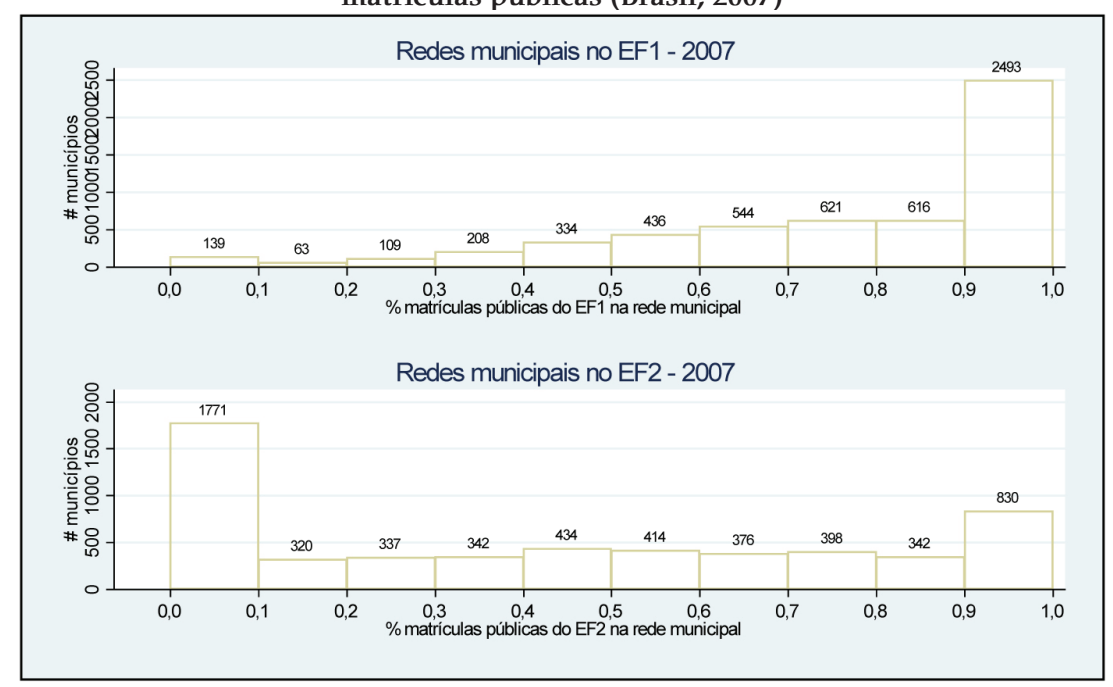

Fonte: INEP, Censo Escolar. 


\section{0 indicador de migração entre redes}

Para representar e quantificar a migração de alunos entre redes, criamos um "indicador de transferência", que procura medir qual o volume de alunos espera-se que mudem de rede do EF1 para o EF2 em um dado município. É importante destacar que o emprego desse indicador é necessário pois não somos capazes de identificar o movimento de migração dos alunos a partir dos dados públicos disponíveis. A fórmula do indicador é a seguinte (para cada município $m$ no ano $t$ ):

$$
I T_{m}=\frac{\text { matrículas rede municipal EF1 }}{\text { matrículas rede públicas EF1 }}-\frac{\text { matrículas rede municipal EF2 }}{\text { matrículas rede públicas EF2 }}
$$

Em termos simplificados os valores representados por esse indicador vão nos indicar o seguinte:

- Se $I T_{m}=-1$, o município tem $100 \%$ das matrículas do EF1 na rede estadual e 100\% do EF2 na municipal. Neste caso, todos os alunos "se transferem" do estado para o município;

- Se $-1<I T_{m}<0$, há "transferência líquida" de parte dos alunos do EF1 estadual para o EF2 municipal;

- Se $I T_{m}=0$, não há "transferência" entre redes (o município tem Ensino Fundamental 100\% municipal ou 100\% estadual);

- Se $0<I T_{m}<1$, há "transferência líquida" de parte dos alunos do EF1 municipal para o EF2 estadual;

- $\quad$ E se $I T_{m}=1$, há "transferência total" do EF1 municipal para o EF2 estadual.

Vale notar que a utilização desse indicador representa uma simplificação importante. Por exemplo, não estamos considerando em detalhe a questão do abandono escolar ou a questão da migração entre redes públicas e privadas. No entanto, como a cobertura do fundamental é bastante elevada e a participação do setor privado relativamente baixa, essa é uma simplificação realista para a grande maioria dos municípios do país.

A distribuição desse indicador de transferência para o ano de 2007 é apresentada no Gráfico 2, abaixo. Podemos observar que havia então quatro grupos claramente distintos. Em primeiro lugar, observa-se a existência de pequeno grupo de municípios com o indicador de transferência inferior a 0 (475 municípios ou menos de $10 \%$ do total). 
São os casos mais raros nos quais há transferência de alunos do primeiro ciclo estadual para o segundo ciclo municipal.

Em segundo lugar, existiam 1.389 municípios (mais de 20\% do total) com indicador de transferência entre 0 e 0,1 , dos quais 674 tinham indicador igual a zero. Trata-se da situação em que o município oferece todo o Ensino Fundamental, não havendo transferência substancial entre redes. Vale notar que não necessariamente toda oferta observada é de natureza municipal. Isso pode ocorrer, mas são também possíveis situações onde município e estado oferecem escolas de dois ciclos, paralelas entre si, sem a ocorrência de transferência de alunos.

Gráfico 2

Distribuição dos municípios segundo o valor do índice de transferência (Brasil, 2007)

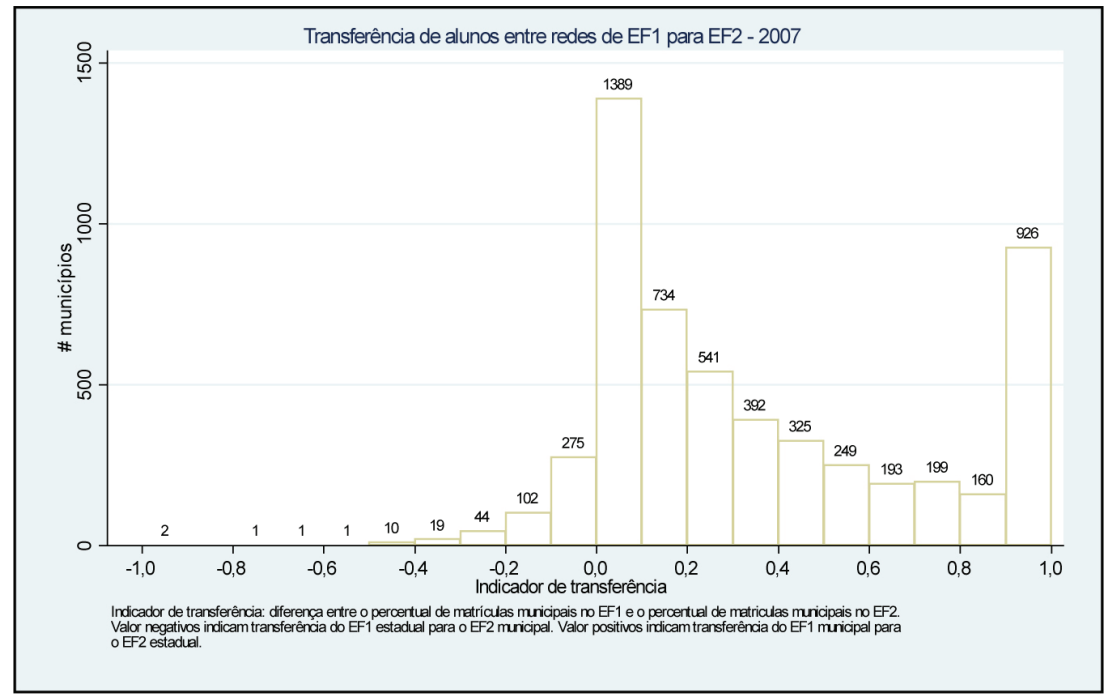

Fonte: INEP, Censo Escolar.

Em terceiro lugar, para 2.793 municípios, ou quase 50\% dos municípios brasileiros, o indicador variava entre 0,1 e 0,9 . Isso significa que, nesse caso, existe transferência entre redes, sendo que em 801 casos essa transferência era bastante intensa, entre 0,5 e 0,9. Trata-se, assim, da situação que denominamos de típica. O município transfere alunos para o segundo ciclo estadual em alguma medida, embora possa contar com algumas escolas que cubram os dois ciclos.

Finalmente, existiam ainda 926 municípios com indicador acima de 0,9 , dos quais 829 tinham indicador igual a 1,0. Nesse caso a tota- 
lidade dos alunos do município no ciclo I é transferida para a rede estadual de ciclo II.

Em outras palavras, o Gráfico 2 evidencia que o fenômeno que pretendemos discutir - a transferência de alunos entre ciclos - era bastante disseminada em 2007. De fato, o indicador de transferência era superior a 0,5 para 1.727 municípios, ou mais de $30 \%$ do total de municípios brasileiros. Para aprofundar essa discussão, apresentamos a seguir os resultados dos cruzamentos entre este indicador e algumas variáveis associadas às características das redes de ensino. Mais adiante, aprofundamos a reflexão sobre o impacto dessas estratégias.

Características dos municípios segundo o grau de transferência de alunos entre redes

Detalhamos inicialmente as informações relativas à distribuição do volume de matrículas segundo o indicador de transferência (Gráfico 3). Podemos observar que os municípios com índices positivos de transferência tinham redes públicas maiores, variando entre 2,5 e 3,5 mil alunos tanto no primeiro quanto no segundo ciclo do Ensino Fundamental ${ }^{5}$.

Gráfico 3

Distribuição do número médio de matrículas no Ensino Fundamental por município, segundo o indicador de transferência (Brasil, 2007)

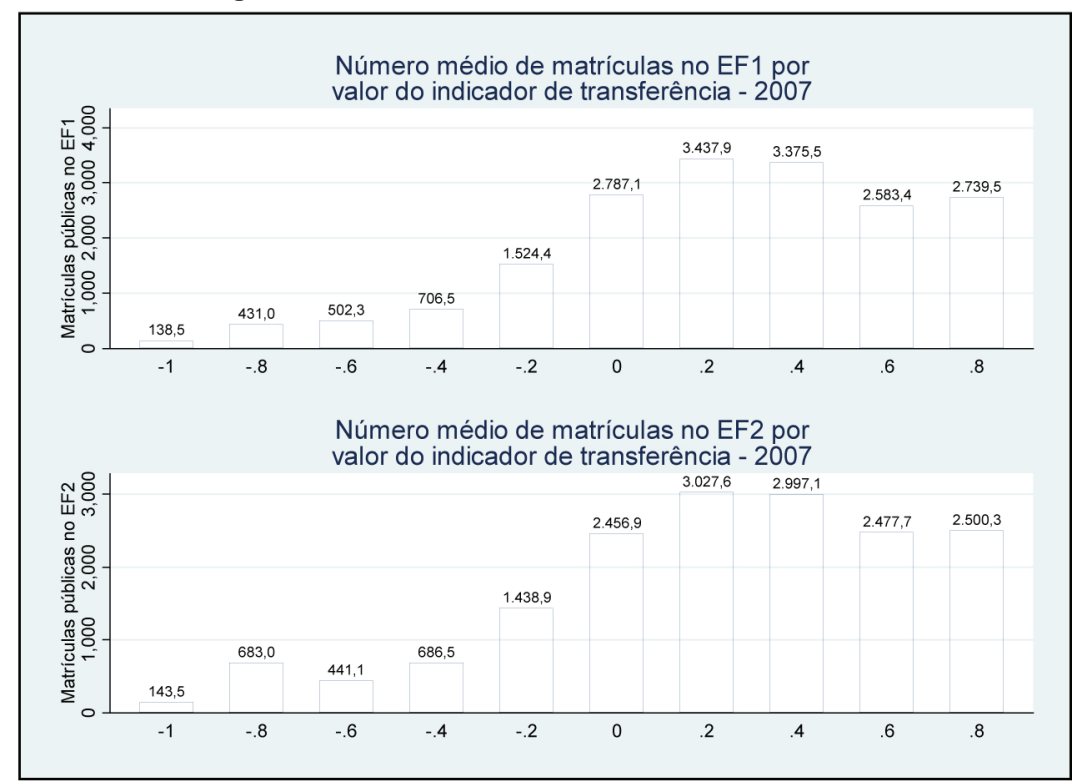

Fonte: INEP, Censo Escolar. 
Em tese, essa deveria ser uma importante dimensão para a reflexão sobre dificuldades de coordenação, já que redes de ensino maiores - e, portanto, mais complexas do ponto de vista da gestão - deveriam apresentar problemas de coordenação mais intensos. Porém é interessante notar que, em média, as redes que faziam pouca transferência (entre 0 e 0,2 ) tinham tamanho médio próximo às que faziam muita transferência (entre 0,8 e 1,0) .

Por outro lado, quando analisamos a distribuição do indicador de transferência segundo a unidade da federação (Gráfico 4), constatamos uma heterogeneidade muito mais significativa. $\mathrm{O}$ caso de São Paulo é emblemático. Esse estado tinha 173 municípios onde não havia transferência, 258 em que a transferência era parcial e 210 onde a transferência é total. Por um lado, apenas 7 estados apresentam números importantes de municípios sem qualquer transferência (Bahia, Ceará, Maranhão, Minas Gerais, Pará, Piauí e São Paulo).

Por outro lado, apenas três estados (MG, PA e SP) apresentavam números substanciais de municípios em que $100 \%$ dos alunos passaram das redes municipais para as estaduais entre o primeiro e o segundo ciclo do Ensino Fundamental. Esses resultados evidenciam que diferentes estratégias relacionadas à municipalização foram adotadas nos estados brasileiros no período posterior ao Fundef, sem que seja possível identificar uma estratégia única para todos os estados brasileiros (Gomes, 2008). 
Gráfico 4

Distribuição do número médio de municípios, segundo padrão do indicador de transferência e segundo a unidade da federação. Brasil, 2007.

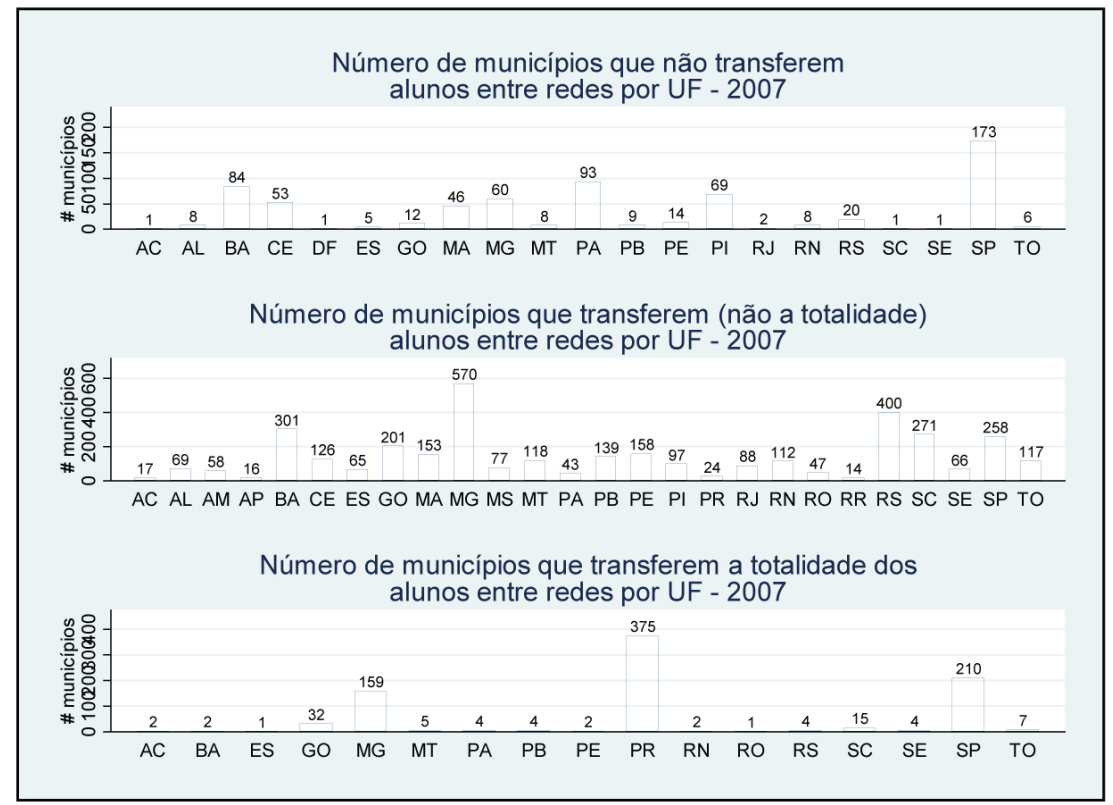

Fonte: INEP, Censo Escolar.

Por último, um aspecto importante a analisar é o relativo ao gasto por aluno desses vários grupos de municípios. O gráfico de dispersão apresentado a seguir (Gráfico 5) mostra uma correlação negativa baixa (da ordem de -0,01) entre o gasto municipal por aluno no Ensino Fundamental e o percentual de alunos que se transferem entre redes. Ou seja, não existem indicações de que a transferência de alunos seja uma função do gasto por alunos. Em outras palavras, não existem elementos aqui para inferirmos, em média, uma racionalidade financeira única nas estratégias de oferta de vagas entre diferentes níveis de transferência de alunos.

Em suma, esses dados sugerem que o índice de transferência parece ser influenciado em alguma medida pelo porte do município, fortemente influenciado pelo tipo de unidade da federação em questão e muito pouco influenciado pelo nível de gasto por aluno do município. Trata-se de um resultado consistente com estudos análogos, como o realizado por Gomes (2008). 
Gráfico 5

Distribuição do gasto municipal por aluno no Ensino Fundamental segundo o indicador de transferência (Brasil, 2007)

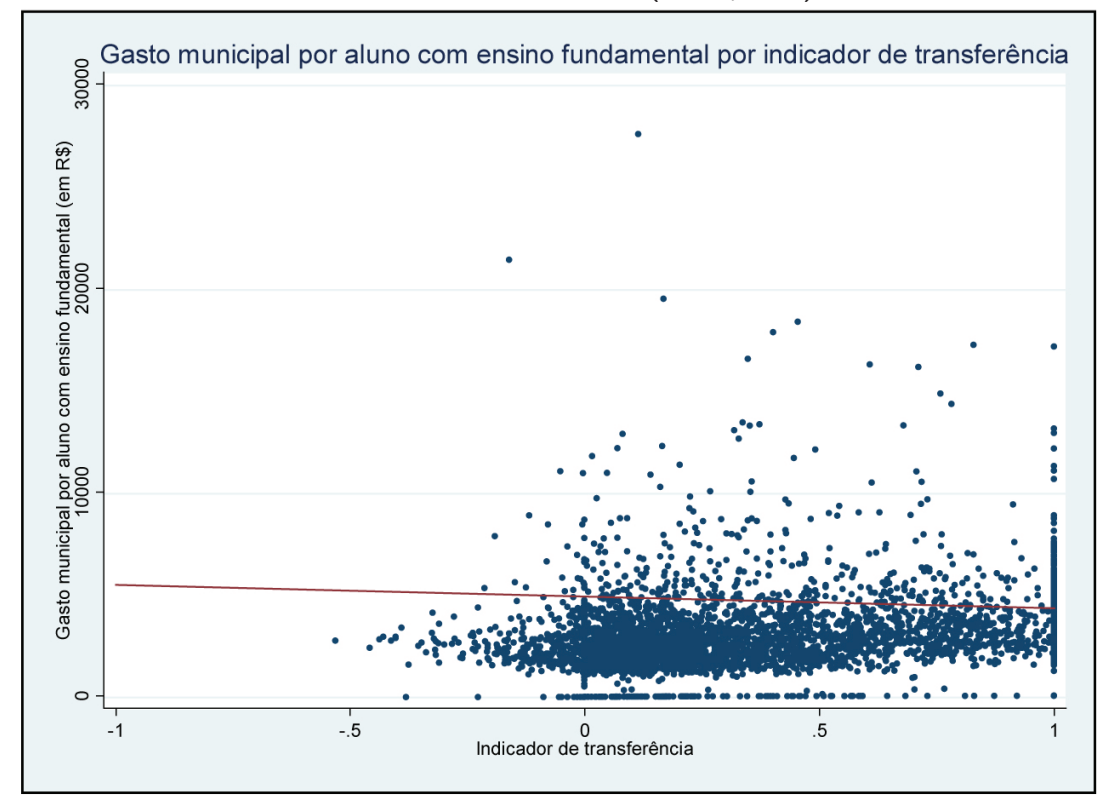

Fonte: INEP, Censo Escolar.

Considerando todas essas características e os dados disponíveis, nosso exercício empírico principal consistirá em acompanhar a evolução do desempenho escolar de coortes de alunos ao longo do Ensino Fundamental que passaram por diferentes "graus" de transferência entre redes municipais e estaduais de ensino. Parte dos alunos seguiu todo o Ensino Fundamental na mesma rede e outra parte começou o fundamental em uma rede, mas teve que migrar para outra. Aprofundamos esses aspectos abaixo.

Impacto da migração entre redes

Para avaliar o impacto da migração entre redes, fixamos a geração que fez o exame de 5o ano da Prova Brasil 2007 e analisamos a evolução do desempenho com a nota dessa mesma geração no $9^{\circ}$ ano (quando fizeram a Prova Brasil 2011). As amostras não são plenamente comparáveis, pois existe evasão e atraso escolar, ou seja, estamos potencialmente comparando grupos diferentes de alunos. É possível equalizar melhor os dois grupos fixando o ano de nascimento dos 
alunos, porém os resultados que veremos à frente são praticamente os mesmos após a aplicação deste filtro.

A modelagem proposta é muito semelhante a uma estratégia de $d i$ ferenças em diferenças, frequentemente utilizada em estudos de avaliação de impacto. No nosso caso, estaríamos considerando como "grupo tratamento" os municípios que transferem seus alunos entre redes de ensino e como "grupo controle" as localidades onde os alunos seguem sempre em uma mesma rede ${ }^{7}$. A diferença aqui é que nossa variável de "tratamento" assume diferentes valores, como se o tratamento tivesse diferentes dosagens medidas segundo o índice de transferência. Formalmente o modelo pode ser descrito como se segue:

$$
Y_{m, t}=\beta_{0}+\beta_{1} d_{t}+\beta_{2} I T_{m}+\beta_{3} d_{t} \cdot I T_{m}+\beta_{4} X_{m, t}+\epsilon_{m, t}
$$

Em que:

$Y_{m, t}:$ nota média na Prova Brasil (em Português ou Matemática) no município $m$ e ano $t=(2007,2011)$;

$d_{t}$ : variável binária que indica o ano ( $=1$ para o ano de 2011, isto é, para o $9^{\circ}$ ano).

$X_{m, t}:$ vetor de variáveis de controle, que incluem: dummies para as Unidades de Federação (UFs); número de matrículas nas redes municipais e estaduais e perfil do alunado.

$\epsilon_{m, t}$ : termo de erro do modelo.

Em termos analíticos, nosso maior interesse recairá sobre o parâmetro $\beta_{3^{\prime}}$ que acompanha a interação entre o ano e o indicador de transferência. Ele dará a estimativa da diferença de desempenho por grau de transferência do alunado da rede municipal no primeiro ciclo para a rede estadual no segundo ciclo.

A interpretação de $\beta_{3}$ pode ser melhor entendida considerando a estrutura de painel do banco de dados. Ao analisar os anos 2007 e 2011 "empilhados", estamos analisando os dados sempre em termos das diferenças entre a nota média do 5o ano em 2007 e a nota média do 9 o ano em 2011. O coeficiente $\beta_{2}$ captura justamente como a nota média da Prova Brasil varia na nossa estrutura temporal, que mistura tem- 
po e etapa de ensino. Naturalmente, este coeficiente deve ser positivo, pois a escala da Prova Brasil é feita de modo que se espera que a nota cresça ao longo das etapas, independente de outros fatores.

Em outras palavras, o coeficiente $\beta_{3}$ capta a diferença na evolução da nota da Prova Brasil entre municípios com alta e baixa taxas de transferência de matrículas. Assim, um valor negativo para $\beta_{3}$ indica que nos municípios com maior índice de transferência, a nota da Prova Brasil cresce menos do que em municípios com menor índice de transferência ${ }^{8}$.

A Tabela A1 do anexo traz as estatísticas descritivas das notas da Prova Brasil e das variáveis de controle, separadas por faixas do índice de transferência. É possível notar que há diferenças de perfil entre municípios que transferem muitas matrículas e os que transferem pouco. Em geral, municípios que transferem menos alunos entre redes tem redes menores e o perfil socioeconômico dos alunos é mais baixo (menor percentual de pais com alta escolaridade e maior percentual de alunos atrasados).

Além disso, é possível notar que municípios que transferem menos alunos têm notas de Português e Matemática de 5o ano mais baixas, mas as notas de 9 a ano não são estatisticamente diferentes entre municípios com mais ou menos transferência. Ou seja, municípios que transferem menos alunos partem de notas mais baixas no $5^{\circ}$ ano, mas chegam no mesmo nível dos municípios que transferem muito, o que indica que os primeiros municípios têm um ganho maior de notas entre $5^{\circ}$ e $9^{\circ}$ anos que os últimos municípios.

Desta forma, este já pode ser um primeiro indicativo de que a transferência de alunos entre redes é negativamente correlacionada com a evolução do desempenho destes alunos ao longo do Ensino Fundamental. Para se chegar a resultados mais robustos, com melhor chance para inferência causal, estimamos os coeficientes do modelo acima, cujos resultados são detalhados na Tabela 1, a seguir.

Essa tabela mostra três especificações do modelo, estimadas para as disciplinas da Prova Brasil. Nas duas primeiras colunas, vemos os modelos sem variáveis de controle. Ele mostra uma correlação mais crua entre a transferência dos alunos e o desempenho agregado do 
município. O que podemos observar nesse caso é que, em média, o desempenho dos alunos de municípios em que há mais transferências entre redes evolui mais lentamente, em comparação com municípios com menos trocas entre redes. O efeito para Língua Portuguesa, no entanto, não é estatisticamente significante.

Ao adicionar as variáveis de controle (colunas 3 e 4) os resultados aumentam em magnitude e precisão, o que mostra que estamos reduzindo o viés gerado pelas diferenças de perfil entre as redes com mais ou menos índice de transferência. Como o indicador de transferência é medido em pontos percentuais, podemos ler o resultado das colunas 3 e 4 como se a cada ponto percentual a mais de "transferência" a evolução das notas entre o $5^{\circ}$ e o $9^{\circ}$ ano fosse 1,6 pontos menor em Português e 3,7 pontos menor em Matemática, segundo a escala da Prova Brasil. É importante notar que os resultados das colunas 3 e 4 foram controlados por variáveis dummies estaduais, o que implica que o impacto da transferência tem uma relação importante com as políticas educacionais de cada estado.

Para interpretar melhor os resultados das colunas 3 e 4, consideremos primeiro as estimativas para $\beta_{1}$. Esse coeficiente indica que, independente do perfil das redes de ensino, as notas da Prova Brasil evoluem, em média, 67,95, em Português, e 60,56, em Matemática, o que, como ressaltamos, é natural, dada a escala da Prova Brasil. Já o coeficiente $\beta_{3}$ mostra que, em média, municípios que transferem mais alunos evoluem 1.640 pontos a menos entre o $5^{\circ}$ e o $9^{\circ}$ ano, em Português, e 3.712 pontos a menos, em Matemática. Ou seja, a cada 1 ponto percentual a mais de transferência entre redes a evolução da nota em Português será, em média, 2,3\% menor que o esperado em Português, e 6,2\% menor, em Matemática.

As duas últimas colunas representam um caso particular bastante relevante. Trata-se de uma comparação entre dois grupos específicos de municípios: aqueles que não transferem seus alunos $(I T=0) \mathrm{e}$ aqueles que transferem todos os alunos $(I T=1)$. O caso é interessante, pois é essa é uma situação em que podemos garantir que os alunos estão de fato tendo que trocar de rede quando passam do primeiro para o segundo ciclo. Em todos os outros casos, parte dos alunos permanece na mesma rede ao longo de todo Ensino Fundamental, o que dificulta a interpretação dos resultados. 
Tabela 1

Estimativas do impacto da transferência entre redes de ensino sobre as notas na Prova Brasil, 2007/2011

\begin{tabular}{|c|c|c|c|c|c|c|}
\hline & (1) & (2) & (3) & (4) & (5) & (6) \\
\hline & \multicolumn{2}{|c|}{ Todos os municípios } & \multicolumn{2}{|c|}{ Todos os municípios } & \multicolumn{2}{|c|}{$\mathrm{IT}=[0 ; 1]$} \\
\hline & Português & Matemática & Português & Matemática & Português & Matemática \\
\hline \multirow{2}{*}{ Efeito tempo $\left(\beta_{1}\right)$} & $66,08^{* * *}$ & $57,39^{* * *}$ & $67,95^{* * *}$ & $60,56^{* * *}$ & $64,72^{* * *}$ & $54,75^{* * *}$ \\
\hline & $(0,426)$ & $(0,491)$ & $(0,460)$ & $(0,550)$ & $(1,340)$ & $(1,613)$ \\
\hline \multirow{2}{*}{$\begin{array}{l}\text { Efeito transferência } \\
\qquad\left(\beta_{2}\right)\end{array}$} & $10,73^{* * *}$ & $11,12^{* * *}$ & 1,040 & $1,435^{*}$ & $-0,476$ & 0,0873 \\
\hline & $(0,858)$ & $(0,988)$ & $(0,709)$ & $(0,859)$ & $(2,779)$ & $(4,011)$ \\
\hline \multirow{2}{*}{$\begin{array}{c}\text { Impacto } \\
\text { transferência }\left(\beta_{3}\right)\end{array}$} & $-0,838$ & $-2,450^{*}$ & $-1,640^{*}$ & $-3,712^{* * *}$ & $-7,144^{* *}$ & $-10,36^{* *}$ \\
\hline & $(1,242)$ & $(1,441)$ & $(0,910)$ & $(1,083)$ & $(3,547)$ & $(4,455)$ \\
\hline \multirow{2}{*}{ Constante $\left(\beta_{0}\right)$} & $165,2^{* * *}$ & $183,1^{* * *}$ & $163,5^{* * *}$ & $172,4^{* * *}$ & $153,3^{* * *}$ & $167,9^{* * *}$ \\
\hline & $(0,283)$ & $(0,319)$ & $(1,274)$ & $(1,421)$ & $(4,764)$ & $(7,309)$ \\
\hline $\begin{array}{l}\text { Variáveis de } \\
\text { controle }\end{array}$ & NÃO & NÃO & SIM & SIM & SIM & SIM \\
\hline N. observações & 12,634 & 12,634 & 12,624 & 12,624 & 1,370 & 1,370 \\
\hline R-quadrado & 0,778 & 0,664 & 0,895 & 0,832 & 0,884 & 0,798 \\
\hline
\end{tabular}

Fonte: Microdados da Prova Brasil 2007 e 2011, Inep/MEC.

Erros-padrão robustos entre parênteses.

${ }^{* * *} \mathrm{p}<0,01,{ }^{* *} \mathrm{p}<0,05,{ }^{*} \mathrm{p}<0,1$

Nota: ${ }^{1}$ Estimativas dos coeficientes principais. Estimativas completas encontram-se na Tabela A2, no Anexo.

As duas últimas colunas mostram, então, que a evolução do desempenho de alunos em municípios onde há necessariamente troca de rede de ensino ao longo do Ensino Fundamental é menor que em municípios nos quais os alunos permanecem sempre na mesma rede. Os níveis observados de impacto são de $-7,1$ pontos, em Português, e $-10,3$ pontos em Matemática9.

Em outras palavras, esses resultados evidenciam de modo bastante claro que a transferência de alunos entre as redes municipal e estadual parece ter impactos substanciais do ponto de vista do desempenho escolar. São resultados relativamente limitados, pois estamos observando a informação na escala de município, que é, evidentemente, uma unidade de análise bastante agregada ${ }^{10}$. Podem também existir resultados espúrios em função de variáveis não observadas pelo modelo. Mas, na medida em que variáveis como porte das redes de ensino, Unidade da Federação e perfil do alunado estão sendo controladas, esses dados sugerem que a transferência em si acarreta impactos relevantes. 


\section{DISCUSSÃO}

A rigor, a falta de articulação entre as secretarias estaduais e municipais de educação tem origens históricas. A educação básica sempre foi assunto dos estados e municípios e, em consequência, os sistemas foram se organizando de forma diferente em cada local, independentemente do papel do governo federal. De fato, com a exceção de políticas de assistência ao estudante, como merenda e transporte escolar; construção de prédios; e apoio didático às escolas por meio do livro didático, o Ministério da Educação (MEC) praticamente ignorou questões voltadas para a qualidade do ensino até o final dos anos 1980.

Assim, chegamos ao início da década de 1990 com um sistema bastante desigual e heterogêneo, alguns sistemas muito "estadualizados" como SP ou com predomínio das redes estaduais como Minas Gerais, Paraná, Rio Grande Sul, Santa Catarina. Mas existiam também sistemas totalmente municipalizados, como na cidade do Rio de Janeiro, ou municipalizados no Ensino Fundamental e estadualizados no Ensino Médio, como era comum no Nordeste. Com a implantação do Fundef, em 1998, esse quadro começou a mudar, mas a cultura mais ou menos descentralizada e de caráter regional já estava enraizada.

A transição do primeiro ciclo do Fundamental para o segundo é sempre complexa, uma vez que o aluno migra de uma situação de professor único, para um modelo de professores especialistas por disciplinas. Trata-se de uma mudança difícil em qualquer contexto, como evidenciado pelos níveis mais elevados de retenção no $6^{\circ}$ ano (Fini, 2014). O que se buscou destacar aqui, no entanto, é que a transferência entre redes acrescenta uma dificuldade adicional a esse difícil momento de passagem.

E se a transferência entre redes for realmente uma proxy razoável para problemas de coordenação entre sistemas - o que parece ser uma hipótese razoável dados os elementos disponíveis - as dificuldades de coordenação são indutoras de um desempenho escolar mais baixo. Evidentemente, tais resultados merecem aprofundamento e especificação de detalhe, tanto relacionados aos tipos de dados utilizados quanto os referidos às diferentes estratégias de coordenação eventualmente avaliadas, que podem ter maior ou menor impacto caso a caso. Afinal, o que faz mais diferença: o planejamento conjunto da 
oferta de vagas ou a coordenação das estratégias pedagógicas e do material didático? Mas os resultados aqui apresentados são instigantes o suficiente para sugerir que essa é uma agenda de pesquisa muito promissora.

Se essa análise puder ser validada por estudos longitudinais baseada em dados individuais de alunos, a migração de alunos das redes municipais para as estaduais poderá emergir como a pedra de toque dos problemas de coordenação. Afinal, em muitos casos, as redes estaduais recebem alunos oriundos de escolas municipais sem nenhuma estratégia de integração acordada previamente.

No caso das redes em que os alunos não migram, ao contrário, o aluno que ingressa no sexto ano encontra, em geral, um contexto mais adequado para a transição entre o Fundamental I e o II, incluindo estratégias de articulação do quesito currículo e capacitação de professores. Outro aspecto relevante diz respeito à criação de oportunidades de recuperação para os alunos no início do ano, permitindo uma gestão do processo de aprendizagem mais adequada.

Em suma, há problemas de coordenação. O cenário hoje continua sendo o de limitada coordenação de ações entre o MEC e os estados; entre o estado e seus municípios; entre o MEC e os municípios; e em vários casos - entre o gestor municipal ou estadual e sua própria rede. Há também problemas de falta de articulação entre os técnicos das secretarias em todos os níveis de ensino e entre diferentes agências federais e locais.

Na prática, isso significa que a gestão administrativa e pedagógica da educação funciona de modo limitado e faltam mecanismos de coordenação entre os níveis de governo. Sem dúvida, esse parece ser um tema de extrema relevância para as políticas de ensino básico no futuro próximo.

(Recebido para publicação em 15 de novembro de 2017)

(Reapresentado em 14 de abril de 2018)

(Reapresentado em 8 de dezembro de 2018)

(Aprovado para publicação em 8 de fevereiro de 2019). 


\section{Haroldo da Gama Torres, Rafael Camelo, Maria Helena Guimarães Castro}

\section{NOTAS}

1. "Rather than isolated actors, sub national authorities and central governments are 'mutually dependent'. In this context, (...) the key underlying question is not whether to "decentralise or not" or even opt for a specific decentralisation model, but to look at ways to improve capacity and co-ordination among public stakeholders at different levels of government to increase efficiency, equity and sustainability of public spending. This question of 'multi level governance' is therefore accurate, whatever the constitutional framework of countries, federal or unitary." (Charbit, 2011:5)

2. Esses agentes podem ou não pertencer a níveis de governo distintos.

3. A rigor, tanto modelos de comando controle quanto os pactuados podem levar a falhas de coordenação, dependendo do seu desenho.

4. O Fundef vigorou até 2006, quando foi substituído pelo Fundo de Manutenção e Desenvolvimento da Educação Básica e de Valorização dos Profissionais da Educação (Fundeb).

5. Esse resultado indica que os casos com índice de transferência negativa se referem mais comumente a situações específicas de municípios de pequeno porte, onde provavelmente a rede municipal está menos estruturada e não foi capaz de se engajar de forma mais organizada na dinâmica mais geral de municipalização. Como se trata de um fenômeno residual, não o consideraremos na análise que se segue.

6. Em outras palavras, no âmbito dos modelos que testaremos mais adiante, esta variável deverá ser menos problemática na comparação entre estes municípios.

7. A opção por modelos do tipo OLS se dá por ser o modelo mais parcimonioso para os propósitos do artigo. Como propõem Angrist e Pischke (2008) quando estamos interessados em efeitos médios de tratamento, modelos como o proposto no artigo são os melhores previsores.

8. Para mais referências sobre o método de diferenças em diferenças, consultar Card e Krueger (1994), Angrist e Pischke (2008) e Imbens e Wooldridge (2009).

9. Como vimos anteriormente, esse modelo dicotômico se refere em grande medida apenas a Minas Gerais, São Paulo e Paraná, que adotaram estratégias de municipalização que estimulavam a migração completa entre redes.

10. Análises mais refinadas poderiam ser feitas a partir da vinculação das informações individuais dos alunos em dois momentos distintos da realização da Prova Brasil (nos $5^{\circ}$ e 9 o anos). Esse tipo de análise depende da disponibilização INEP da base de dados da Prova Brasil com um formato que permita a vinculação. 


\section{REFERÊNCIAS BIBLIOGRÁFICAS}

ANGRIST, Joshua D.; PISCHKE, Jorn-Steffen. (2008). Mostly harmless econometrics: an empiricist's companion. Princeton University Press.

ARRETCHE, Marta. (2009), “Descentralização das políticas públicas sociais no marco pós-Constituição de 1988: experiências e perspectivas". In: Cedeplar (org.), Projeto perspectivas dos investimentos sociais no Brasil. Belo Horizonte: Cedeplar.

. (2010), "Federalismo e Igualdade Territorial em Termos?". DADOS - Revista de Ciências Sociais, v. 53, n. 3, pp. 587-620. 2010.

CARD, David; KRUEGER, Alan B. (1994), “Minimum wages and employment: a case study of the fast-food industry in New Jersey and Pennsylvania". American Economic Review, v. 84, n. 4.

CASTRO, Maria Helena Guimarães. (2015), "Role of states and municipalities in the implementation of education policies (Brazil)". In: S. Schwartzman (ed.), Education in South America. London: Bloomsbury Academic, 2015.

CHARBIT, Claire. (2011), "Governance of public policies in decentralised contexts: the multi-level approach". OECD Regional Development Working Papers. 2011/04, OECD Publishing, 2011. Disponível em: http://dx.doi.org/10.1787/5kg883pkxkhc-en. Acesso em 27 de setembro de 2019.

COOPER, Russel; ANDREW, John. (1991), “Coordinating Coordination Failures”. In: N. G. Mankiw; D. Romer (eds.), New Keynesian Economics. Cambridge: MIT Press.

COSTA, Bruno Lazzarotti Diniz; DUARTE, Vanda Catarina. (2008), “Os efeitos do FUNDEF nas políticas educacionais dos municípios mineiros". Educ. rev. [online], n. 48, pp. 143-70. Disponível em: http://dx.doi.org/10.1590/S0102-46982008000200008. Acesso em 27 de setembro de 2019.

COSTA, Leandro Oliveira; CARNOY, Martin. (2015), “The effectiveness of an early-grade literacy intervention on the cognitive achievement of brazilian students". In: Educational Evaluation and Policy Analysis Month. pp. 1-24. Disponível em: https://lemanncenter.stanford.edu/sites/default/files/Martin_Leandro_the\%20Effectiviness $\% 20$ Early\%20Grade\%20best\%2010\%203102_0162373715571437\%20(1).pdf. Acesso em 27 de setembro de 2019.

COX, Gary W. (1997), Making votes count: strategic coordination in the world's electoral systems. New York: Cambridge University Press.

FINI, Maria Inês. (2014), “Currículo e Avaliação: uma articulação necessária”. In: M. H. G. Castro; B. Negri; H. Torres. (orgs.), Educação Básica no Estado de São Paulo: avanços e novos desafios. São Paulo: SEADE/FDE.

FRANCO, Creso; ALVES, Fátima; BONAMINO, Alicia. (2007), “Qualidade do Ensino Fundamental: políticas, suas possiblidades, seus limites". Educação e Sociedade, v. 28, n. 100, pp. 989-1014.

GOMES, Sandra C. (2008), Fatores explicativos das diferentes estratégias de municipalização do Ensino Fundamental nos governos subnacionais do Brasil (1997-2000). Tese de Doutorado (Ciência Política). São Paulo: USP. 


\section{Haroldo da Gama Torres, Rafael Camelo, Maria Helena Guimarães Castro}

LAC/Banco Mundial. (2010), La formulación de políticas en la OCDE: Ideas para América Latina. Washington: Governo da Espanha/Banco Mundial.

MORDUCHOWICZ, Alejandro; ARANGO, Aída. (2010), “Desenho institucional e articulação do federalismo educativo: experiências internacionais". In: R. Portela; W. Santana (orgs.), Educação e federalismo no Brasil: combater as desigualdades, garantir a diversidade. Brasília: UNESCO.

SALES, Luís Carlos; SILVA, Magna J. G. (2013), e. "A movimentação das matrículas no Ensino Fundamental no estado do Piauí". Educ. Real. [online], v. 38, n. 4, pp. 1283-301. Disponível em: http://dx.doi.org/10.1590/S2175-62362013000400015. Acesso em 27 de setembro de 2019.

SANTOS, Maurício Pastor; GISI, Maria Lourdes. (2017), “A (des)articulação do Ensino Fundamental e a formação dos professores". Rev. Bras. Estud. Pedagog. [online], v. 98, n. 248, pp. 47-61. Disponível em: http://dx.doi.org/10.24109/2176-6681.rbep.98i248.2526.

SANTOS, Jussara Maria Tavares Puglielli. (2003), "O processo de municipalização no estado do Paraná". Educ. rev. [online], n. 22, pp. 257-79. Disponível em: http://dx.doi. org/10.1590/0104-4060.321. Acesso em 27 de setembro de 2019.

SEE-MG. Secretaria de Estado de Educação de Minas Gerais. (2012), Programa de Intervenção Pedagógica: Alfabetização no Tempo Certo Municipal. Belo Horizonte: SEE-MG. Disponível em: https://www.educacao.mg.gov.br/images/stories/pip/pip_municipal.pdf. Acesso em 1 de julho de 2015.

TORRES, Haroldo da Gama et al. (2008), “Educação na periferia de São Paulo: ou como pensar as desigualdades educacionais?". In: L. C. de Q. Ribeiro; R. Kaztman (orgs.), A cidade contra a escola: segregação urbana e desigualdades educacionais em grandes cidades da América Latina. Rio de Janeiro: Letra Capital.

TAVARES, Tais Moura. (2003), “Gestão municipal da educação, organização do sistema nacional e regime de colaboração: algumas questões". In: Educ. rev. [online], n. 22, pp. 241-56. Disponível em: http:/ /dx.doi.org/10.1590/0104-4060.320. Acesso em 27 de setembro de 2019.

VIEIRA, Sofia Lerche; VIDAL, Eloísa Maia. (2013), “Construindo uma história de colaboração na educação: a experiência do Ceará". Educ. Soc. [online], v. 34, n. 125, pp. 1075-933. Disponível em: http://dx.doi.org/10.1590/S0101-73302013000400004. Acesso em 27 de setembro de 2019. 


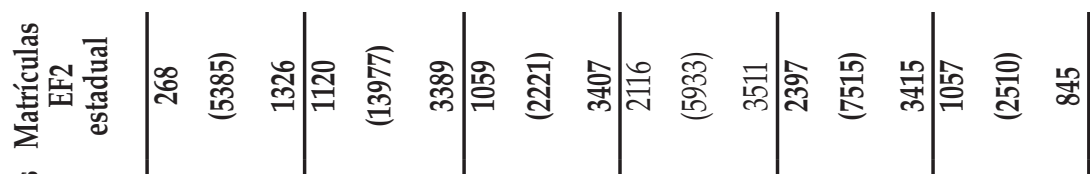

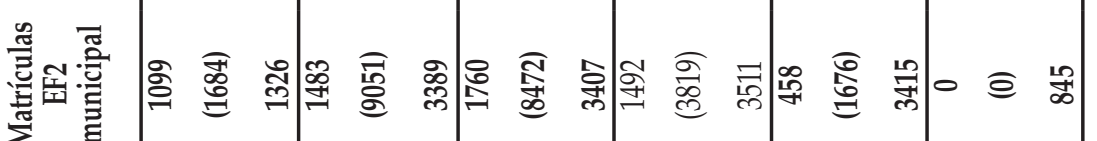

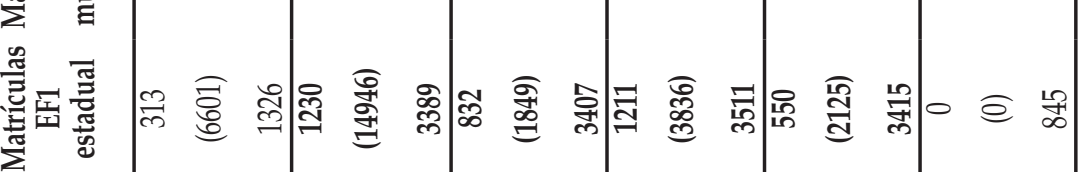

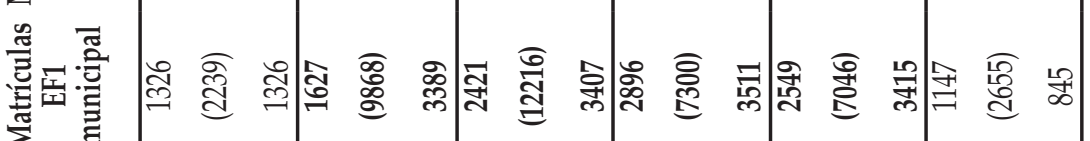

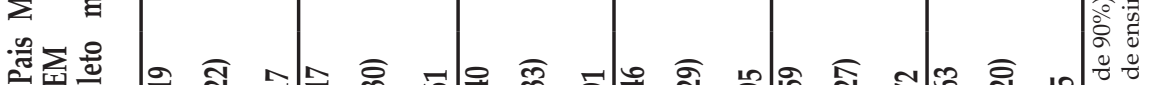

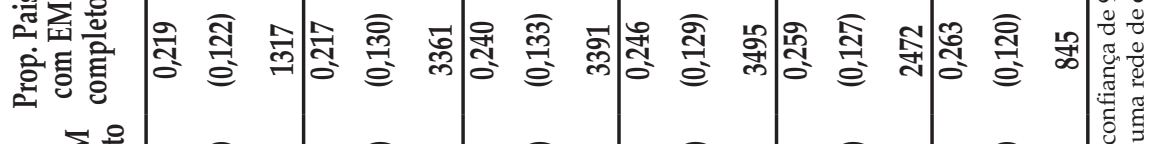

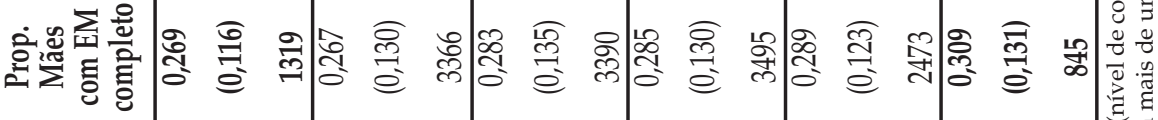

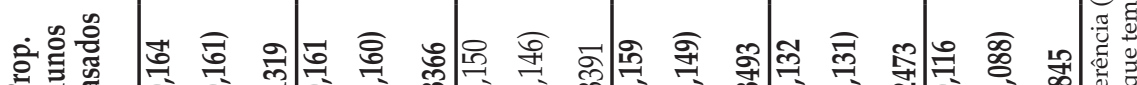

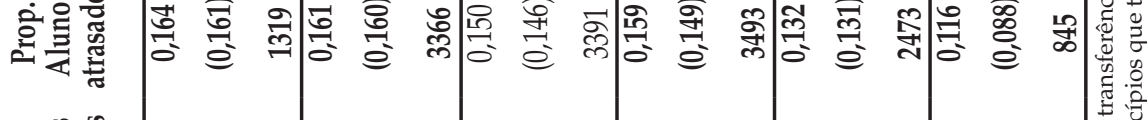

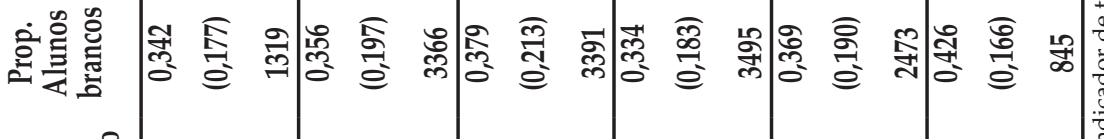

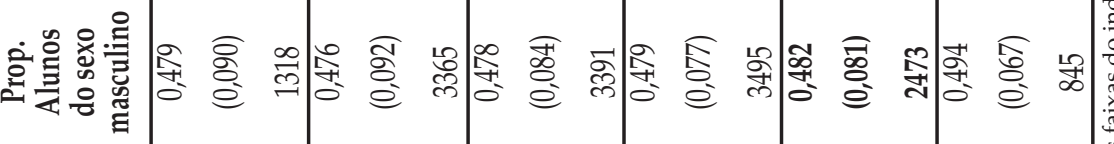

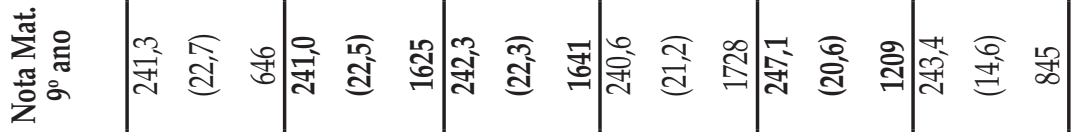

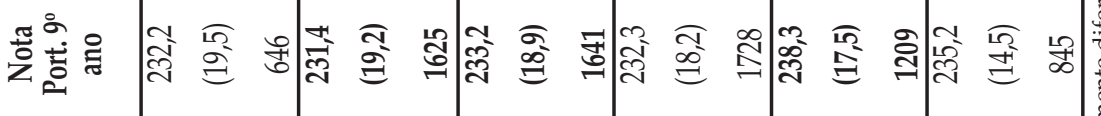

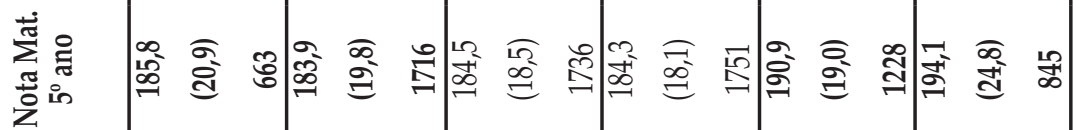

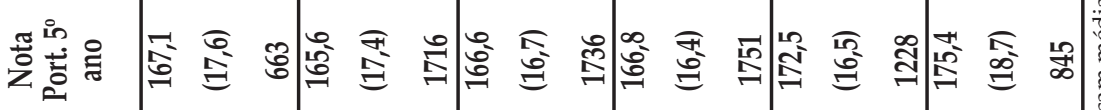

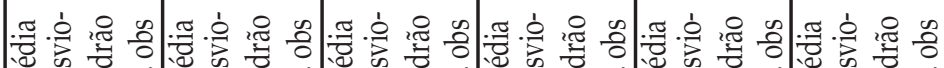

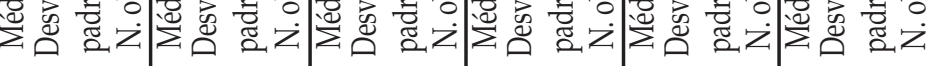

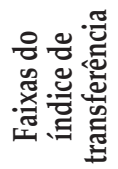

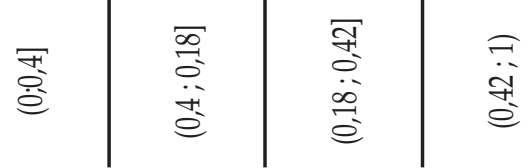


Haroldo da Gama Torres, Rafael Camelo, Maria Helena Guimarães Castro

Tabela A2 - Estimativas completas do modelo de diferenças em diferenças

\begin{tabular}{|c|c|c|c|c|c|c|}
\hline & \multicolumn{2}{|c|}{ Todos os municípios } & \multicolumn{2}{|c|}{ Todos os municípios } & \multicolumn{2}{|c|}{$\mathrm{IT}=[0 ; 1]$} \\
\hline & Português & Matemática & Português & Matemática & Português & Matemática \\
\hline Efeito tempo & $66.08^{* * *}$ & $57.39^{* * *}$ & $67.95^{* * *}$ & $60.56^{* * *}$ & $64.72^{* * *}$ & $54.75^{* * *}$ \\
\hline (beta 1) & $(0.426)$ & $(0.491)$ & $(0.460)$ & $(0.550)$ & $(1.340)$ & (1.613) \\
\hline Efeito & $10.73^{* * *}$ & $11.12^{* * *}$ & 1.040 & $1.435^{*}$ & -0.476 & 0.0873 \\
\hline $\begin{array}{l}\text { transterência } \\
\text { (beta 2) }\end{array}$ & (0.858) & (0.988) & $(0.709)$ & (0.859) & $(2.779)$ & $(4.011)$ \\
\hline Impacto & -0.838 & $-2.450^{*}$ & $-1.640^{*}$ & $-3.712^{* * *}$ & $-7.144^{* *}$ & $-10.36^{* *}$ \\
\hline $\begin{array}{l}\text { transterencia } \\
\text { (beta 3) }\end{array}$ & $(1.242)$ & $(1.441)$ & $(0.910)$ & $(1.083)$ & $(3.547)$ & $(4.455)$ \\
\hline $\begin{array}{l}\text { Dummies } \\
\text { de UF } \\
\text { (Rondôninia } \\
\text { é default) } \\
\end{array}$ & & & & & & \\
\hline Acre & & & $\begin{array}{c}-6.497^{* * *} \\
(1.675)\end{array}$ & $\begin{array}{c}-8.474^{* * *} \\
(1.744)\end{array}$ & & \\
\hline Amazonas & & & $\begin{array}{c}-4.605^{* * *} \\
(1.170) \\
\end{array}$ & $\begin{array}{l}-3.894^{* *} \\
(1.525) \\
\end{array}$ & & \\
\hline Amapá & & & $\begin{array}{c}-12.74^{* * *} \\
(1.954)\end{array}$ & $\begin{array}{c}-13.33^{* * *} \\
(1.814)\end{array}$ & & \\
\hline Amazonas & & & $\begin{array}{c}-8.126^{* * *} \\
(0.961) \\
\end{array}$ & $\begin{array}{c}-9.657^{* * *} \\
(1.065) \\
\end{array}$ & $\begin{array}{c}4.493 \\
(3.449) \\
\end{array}$ & $\begin{array}{r}1.694 \\
(6.216) \\
\end{array}$ \\
\hline Pará & & & $\begin{array}{c}-16.02^{* * *} \\
(1.466)\end{array}$ & $\begin{array}{c}-18.38^{* * *} \\
(1.488)\end{array}$ & & \\
\hline Tocantins & & & $\begin{array}{c}-7.249^{* * *} \\
(0.983)\end{array}$ & $\begin{array}{c}-8.127^{* * *} \\
(1.114)\end{array}$ & $\begin{array}{l}14.95^{* * *} \\
(4.808)\end{array}$ & $\begin{array}{l}14.30^{*} \\
(7.834)\end{array}$ \\
\hline Maranhão & & & $\begin{array}{c}-14.63^{* * *} \\
(0.877)\end{array}$ & $\begin{array}{c}-16.09^{* * *} \\
(1.030)\end{array}$ & $\begin{array}{l}-2.952 \\
(3.521)\end{array}$ & $\begin{array}{l}-3.158 \\
(6.424)\end{array}$ \\
\hline Piauí & & & $\begin{array}{c}-5.930^{* * *} \\
(0.940) \\
\end{array}$ & $\begin{array}{c}-4.930^{* * *} \\
(1.061)\end{array}$ & $\begin{array}{c}4.440 \\
(3.614) \\
\end{array}$ & $\begin{array}{c}2.863 \\
(6.322) \\
\end{array}$ \\
\hline Ceará & & & $\begin{array}{c}-6.513^{* * *} \\
(0.968) \\
\end{array}$ & $\begin{array}{c}-8.045^{* * *} \\
(1.104)\end{array}$ & $\begin{array}{l}7.273^{* *} \\
(3.609)\end{array}$ & $\begin{array}{c}4.118 \\
(6.359) \\
\end{array}$ \\
\hline $\begin{array}{l}\text { Rio Grande } \\
\text { do Norte }\end{array}$ & & & $\begin{array}{c}-14.78^{* * *} \\
(0.921) \\
\end{array}$ & $\begin{array}{c}-15.50^{* * *} \\
(1.008) \\
\end{array}$ & $\begin{array}{c}0.496 \\
(4.031) \\
\end{array}$ & $\begin{array}{c}0.195 \\
(6.645) \\
\end{array}$ \\
\hline Paraíba & & & $\begin{array}{c}-9.457^{* * *} \\
(0.895) \\
\end{array}$ & $\begin{array}{c}-9.671^{* * *} \\
(1.007)\end{array}$ & $\begin{array}{c}5.117 \\
(3.969) \\
\end{array}$ & $\begin{array}{c}5.231 \\
(6.714) \\
\end{array}$ \\
\hline Pernambuco & & & $\begin{array}{c}-9.343^{* * *} \\
(0.889)\end{array}$ & $\begin{array}{c}-9.509^{* * *} \\
(1.016)\end{array}$ & $\begin{array}{c}3.782 \\
(3.926)\end{array}$ & $\begin{array}{c}2.016 \\
(6.540)\end{array}$ \\
\hline Alagoas & & & $\begin{array}{c}-15.28^{* * *} \\
(0.946)\end{array}$ & $\begin{array}{c}-15.39^{* * *} \\
(1.073)\end{array}$ & $\begin{array}{l}-0.634 \\
(3.558)\end{array}$ & $\begin{array}{l}-1.229 \\
(6.460)\end{array}$ \\
\hline
\end{tabular}


Tabela A2 - Estimativas completas do modelo de diferenças em diferenças (cont.)

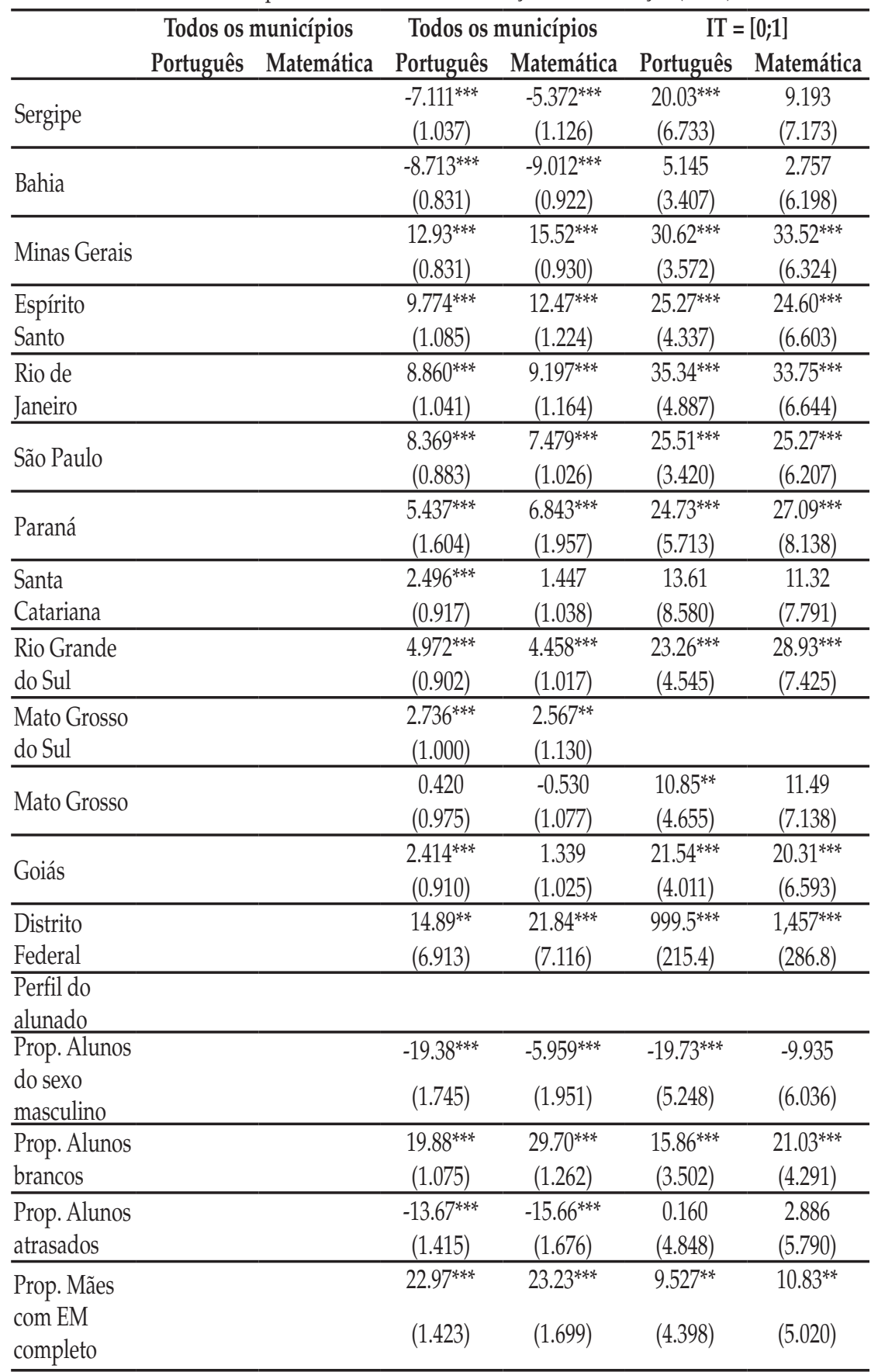


Haroldo da Gama Torres, Rafael Camelo, Maria Helena Guimarães Castro

Tabela A2 - Estimativas completas do modelo de diferenças em diferenças (cont.)

\begin{tabular}{|c|c|c|c|c|c|c|}
\hline & \multicolumn{2}{|c|}{ Todos os municípios } & \multicolumn{2}{|c|}{ Todos os municípios } & \multicolumn{2}{|c|}{$\mathrm{IT}=[0 ; 1]$} \\
\hline & Português & Matemática & Português & Matemática & Português & Matemática \\
\hline Prop. Pais & & & $6.992^{* * *}$ & 1.877 & $11.15^{* *}$ & 3.666 \\
\hline $\begin{array}{l}\text { com EM } \\
\text { completo }\end{array}$ & & & $(1.401)$ & (1.616) & $(4.534)$ & $(5.206)$ \\
\hline $\begin{array}{l}\text { Tamanho } \\
\text { das redes }\end{array}$ & & & & & & \\
\hline Matrículas & & & $0.000152^{* *}$ & $2.28 \mathrm{e}-05$ & $0.00229^{* * *}$ & $0.00163^{* * *}$ \\
\hline $\begin{array}{l}\text { EF1 } \\
\text { municipal }\end{array}$ & & & $(7.04 \mathrm{e}-05)$ & (7.54e-05) & $(0.000521)$ & $(0.000557)$ \\
\hline Matrículas & & & $9.09 \mathrm{e}-05$ & $1.41 \mathrm{e}-05$ & $-0.00371^{* * *}$ & $-0.00687^{* * *}$ \\
\hline EF1 estadual & & & $(6.74 \mathrm{e}-05)$ & $(7.41 \mathrm{e}-05)$ & $(0.00142)$ & $(0.00182)$ \\
\hline Matrículas & & & $-0.000170^{*}$ & $-1.67 \mathrm{e}-05$ & $-0.00255^{* * *}$ & $-0.00201^{* * *}$ \\
\hline $\begin{array}{l}\text { EF2 } \\
\text { municipal }\end{array}$ & & & $(8.79 \mathrm{e}-05)$ & $(9.79 \mathrm{e}-05)$ & $(0.000650)$ & (0.000709) \\
\hline Matrículas & & & $-0.000121^{*}$ & $-6.70 \mathrm{e}-05$ & $-0.00246^{* * *}$ & $-0.00187^{* * *}$ \\
\hline EF2 estadual & & & $(6.67 \mathrm{e}-05)$ & (7.08e-05) & $(0.000652)$ & $(0.000684)$ \\
\hline $\begin{array}{l}\text { Constante } \\
\text { (beta 0) }\end{array}$ & $\begin{array}{l}165.2^{* * *} \\
(0.283)\end{array}$ & $\begin{array}{c}183.1^{* * *} \\
(0.319)\end{array}$ & $\begin{array}{l}163.5^{* * *} \\
(1.274)\end{array}$ & $\begin{array}{l}172.4^{* * *} \\
(1.421)\end{array}$ & $\begin{array}{l}153.3^{* * *} \\
(4.764)\end{array}$ & $\begin{array}{l}167.9^{* * *} \\
(7.309)\end{array}$ \\
\hline N. obs. & 12,634 & 12,634 & 12,624 & 12,624 & 1,370 & 1,370 \\
\hline R quadrado & 0.778 & 0.664 & 0.895 & 0.832 & 0.884 & 0.798 \\
\hline
\end{tabular}


RESUMO

Dificuldades de Coordenação e Politicas Educacionais no Brasil: O Caso do Ensino Fundamental

O artigo busca investigar o problema das falhas de coordenação no âmbito da política de Ensino Fundamental do Brasil. Os autores assumem que a migração de alunos entre redes municipais e estaduais ao longo do Ensino Fundamental pode ser considerada uma proxy de falha de coordenação no âmbito dessa política, com reflexos negativos nos termos do desempenho escolar. A análise empírica apresentada, baseada em um painel longitudinal de municípios para o período de 2007 a 2011, mostra que a transferência de alunos entre redes faz com que a evolução das notas entre o 5o e o 9o ano seja 3,6 pontos menor em Português e 5,3 pontos menor em Matemática, segundo a escala da Prova Brasil.

Palavras-chaves: Implementação de políticas públicas; política social; educação; falhas de coordenação; Ensino Fundamental

\section{ABSTRACT \\ Difficulties of Coordination and Educational Policies in Brazil: The Case of Elementary Education}

The article seeks to investigate the problem of coordination failures within the framework of the Brazilian primary education policy. The authors assume that the migration of students between the municipal and state school systems throughout Elementary School can be considered a proxy for coordination failure within the framework of this policy, with negative consequences in terms of school performance. The empirical analysis presented, based on a longitudinal panel of municipalities for the period of 2007 to 2011, shows that the transfer of students between systems has an impact on the evolution of grades, which between the 5th and 9th grades is 3.6 points lower in Portuguese and 5.3 points lower in Mathematics, according to the scale of the so-called Prova Brasil (test that evaluates Brazilian public education).

Keywords: Implementation of public policies; social policy; education; failure of coordination; Elementary School 


\section{RÉSUMÉ \\ Les Difficultés de Coordination et les Politiques Éducatives au Brésil: Le Cas de l'Enseignement Fondamental}

L'article cherche à examiner le problème des défaillances de la coordination dans le cadre de la politique concernant à l’Enseignement Fondamental brésilien. Les auteurs partent du principe que la migration des élèves entre les réseaux publiques des municipes et des états, au cours de l'Enseignemant Fondamental, peut être considérée comme un indicateur de l'échec de la coordination dans le cadre de cette politique, en arrivant à conséquences négatives sur les résultats scolaires. L'analyse empirique présentée, basée sur un panel longitudinal de municipalités pour la période 2007-2011, montre que le transfert d'étudiants entre les années détermine que l'évolution des notes dans les segments de la $5^{\text {ème }}$ et de la $9^{\text {ème }}$ années soit inférieure à 3,6 points, dans la discipline de langue portugaise, et à 5,3 points plus bas dans les mathématiques, selon l'échelle de Prova Brasil.

Mots-clés: Mise-en-Ouvre des politiques publiques; politique sociale; éducation; échec de la coordination; Enseingnement Fondamental

\section{RESUMEN \\ Dificultades de Coordinación de Políticas Educacionales en Brasil: El Caso de la Enseñanza Fundamental}

El artículo pretende investigar el problema de las fallas de coordinación en el ámbito de la política de Enseñanza Fundamental en Brasil. Los autores asumen que la migración de alumnos entre redes municipales y estaduales a lo largo de la Enseñanza Fundamental, puede ser considerada una proxy de falla de coordinación en el ámbito de esa política, con reflejos negativos en términos del desempeño escolar. El análisis empírico presentado, basado en un panel longitudinal de municipios para el periodo de 2007 a 2011, muestra que la transferencia de alumnos entre redes hace que a evolución de las notas entre el $5^{\circ}$ y el $9^{\circ}$ año sea de 3,6 pontos menos en Portugués y 5,3 pontos menos en Matemática, según la escala de la Prueba Brasil.

Palabras clave: Implementación de políticas públicas; política social; educación; fallas de coordinación; Enseñanza Fundamental 